\title{
Suppression of Kainate-Evoked AMPA Receptor Mediated Responses by Lanthanum in Rat Sacral Dorsal Commissural Neurons
}

\author{
Zhen Hong ${ }^{a}$ Dian-Shi Wang ${ }^{a}$ Shun-Yan Lu ${ }^{b}$ Ji-Shuo Li ${ }^{a}$ \\ ${ }^{a}$ Department of Anatomy and K.K. Leung Brain Research Centre and ${ }^{\mathrm{b}}$ Department of Physiology, \\ Fourth Military Medical University, Xi'an, China
}

\section{Key Words}

Lanthanum $\cdot$ Kainate $\cdot \alpha$-Amino-3-hydroxy-5-methyl-

4-isoxazolepropionic acid receptor - Sacral dorsal

commissural nucleus · Nystatin-perforated

patch-clamp technique

\begin{abstract}
The effect of lanthanum (La) on kainate (KA) responses in neurons acutely dissociated from the rat sacral dorsal commissural nucleus (SDCN) was investigated using the nystatin-perforated patch-recording configuration under voltage-clamp conditions. The responses to KA were mediated by activation of the $\alpha$-amino-3-hydroxy-5-methyl4-isoxazolepropionic acid (AMPA) receptors in SDCN neurons. $\mathrm{La}^{3+}$ reversibly inhibited KA $(100 \mu \mathrm{M})$ activated currents $\left(I_{K A}\right)$ in a concentration-dependent manner over the range from $30 \mu M$ to $30 \mathrm{mM}$, with $I_{50}$ values of 0.64 $\pm 0.06 \mathrm{mM}$ at a holding potential $\left(\mathrm{V}_{\mathrm{H}}\right)$ of $-40 \mathrm{mV}$. Our further study indicated that the effects of $\mathrm{La}^{3+}$ on $I_{\mathrm{KA}}$ were voltage independent. Moreover, the inhibition was not use dependent and was not overcome by increasing the concentration of agonist. These findings indicate that $\mathrm{La}^{3+}$ is an efficacious inhibitor of AMPA receptor mediated responses which may contribute to its cytotoxic effect.
\end{abstract}

Copyright (C) 2004 S. Karger AG, Basel

\section{Introduction}

Lanthanum $(\mathrm{La})$ is a trivalent rare earth element that is of increasing interest to toxicologists. It is not only a by-product of the nuclear industry, but also increasingly used in the manufacture of metals with special properties. Greater use of La increases the chances of accidental exposure, both acute and chronic. Early studies have found reductions in the number of successful pregnancies in mice injected with La [1] and failure of cephalic neural tube closure in rat embryos exposed to the ion [2]. La is also a potential behavioral teratogen [3]. The above facts, in addition to its complicated pharmacological properties [4], justify attempts to characterize the effects of $\mathrm{La}^{3+}$ on neurotransmitter receptors and synaptic responses.

La has been reported to influence neuronal transmitter systems. Most studied properties are the effects of $\mathrm{La}^{3+}$ on the $\gamma$-aminobutyric acid type A receptor function [57], and it has also been shown that $\mathrm{La}^{3+}$ could modulate glycine currents in rat septal cholinergic neurons in culture [8] as well as acetylcholine-induced currents in guinea pig ileal smooth muscle cells [9]. Glutamate receptor induced responses can also be affected by $\mathrm{La}$ in various preparations, including rat dorsal root ganglia (DRG), cultured rat hippocampal and cortical neurons [10,11], and rat dorsal horn neurons [12]. In these studies, $\mathrm{La}^{3+}$ displayed a biphasic effect on $\alpha$-amino-3-hydroxy5-methyl-4-isoxazolepropionic acid (AMPA) receptor

\section{KARGER}

Fax +4161306 1234 E-Mailkarger@karger.ch www.karger.com
Dr. Dian-Shi Wang

Department of Anatomy and K.K. Leung Brain Research Centre

Fourth Military Medical University, 17 West Changle Road

Xi'an 710032 (China)

Tel. +86298337 4501, Fax +86 298328 3229, E-Mail dianshiw@yahoo.com 
mediated responses, i.e., low concentrations of $\mathrm{La}^{3+}(1-$ $100 \mu M)$ potentiated AMPA receptor mediated currents, while the currents were blocked by $\mathrm{La}^{3+}>100 \mu M$.

The sacral dorsal commissural nucleus (SDCN) represents the dorsal gray matter of the central canal in the lower lumbar and sacral spinal cord. Our previous work [13] has shown some distinctive characteristics of AMPA receptors in the SDCN: the lack of the glutamate receptor 2 subunit and the presence of flip forms of receptors. These raise the possibility that the effects of $\mathrm{La}^{3+}$ on AMPA receptors are different between SDCN and other brain regions, and the distinctness may add further diversity to the pharmacological properties of $\mathrm{La}^{3+}$. Therefore, the effect of this metal on AMPA receptor mediated responses evoked by kainate (KA) was investigated using the nystatin-perforated patch-recording configuration in SDCN neurons.

\section{Materials and Methods}

\section{Preparation}

The SDCN neurons were acutely dissociated as described elsewhere [14]. Two-week-old Sprague-Dawley rats were anesthetized with sodium pentobarbitone $(50 \mathrm{mg} / \mathrm{kg}$ i.p.), and laminectomy was performed to expose the lower lumbar and sacral spinal cord. The lumbosacral $\left(\mathrm{L}_{6}-\mathrm{S}_{2}\right)$ segment (approximately $10-15 \mathrm{~mm}$ ) was dissected out from the spinal cord and immersed in freezing incubation solution, followed by animal decapitation. After removing the attached dorsal rootlets and the pia mater, the spinal segment was affixed with cyanoacrylic glue to a $10 \times 15-\mathrm{mm}$ agar base with the latter supporting the spinal block. The tissue block together with the agar base was positioned onto the bottom of the cutting chamber of a vibratome tissue slicer (DTK-1000; Dosaka, Kyoto, Japan), with the dorsal surface of the cord facing the vibrating blade. Cold incubation solution (approximately $5{ }^{\circ} \mathrm{C}$; see below) aerated with $95 \% \mathrm{O}_{2}$ and $5 \% \mathrm{CO}_{2}$ was subsequently poured into the chamber to immerse the spinal block. The spinal segment was sectioned to yield several transverse slices ( $400 \mu \mathrm{m}$ thick) containing the SDCN region. The slices were preincubated in oxygenated incubation solution (see below) for $50 \mathrm{~min}$ at room temperature $\left(22-25^{\circ} \mathrm{C}\right)$. Thereafter, the slices were treated enzymatically in oxygenated incubation solution containing $1 \mathrm{mg}(6-8 \mathrm{ml})$ pronase for $20 \mathrm{~min}$ at $31^{\circ} \mathrm{C}$, followed by exposure to $1 \mathrm{mg}(6-8 \mathrm{ml})$ thermolysin for $15 \mathrm{~min}$ under identical conditions. After enzymatic treatment, the slices were kept in enzyme-free incubation solution for $1 \mathrm{~h}$. Then a portion of SDCN region was micropunched out by using an electrolytically polished injection needle and transferred into a culture dish filled with standard external solution (see below). Neurons were mechanically dissociated with fire-polished Pasteur pipettes under visual guidance by means of a phase-contrast microscope (model IX70; Olympus, Tokyo, Japan). The dissociated neurons adhered to the bottom of the dish within $20 \mathrm{~min}$, allowing electrophysiological studies to be conducted. Neurons that retained their original morphological features, such as the dendritic processes, were then used for the experiments. The experimental procedures have been ap- proved by the Animal Care and Use Committee of the Fourth Military Medical University.

\section{Solutions}

The incubation solution (containing in $\mathrm{m} M$ : $\mathrm{NaCl} 124$, $\mathrm{NaHCO}_{3} 24, \mathrm{KCl} 5, \mathrm{KH}_{2} \mathrm{PO}_{4} 1.2, \mathrm{CaCl}_{2} 2.4, \mathrm{MgSO}_{4} 1.3$, and glucose 10 ) was aerated with $95 \% \mathrm{O}_{2}$ and $5 \% \mathrm{CO}_{2}$ to a final $\mathrm{pH}$ of 7.4 . The normal external standard solution (containing in $\mathrm{mM}: \mathrm{NaCl}$ $150, \mathrm{KCl} 5, \mathrm{CaCl}_{2} 2, \mathrm{MgCl}_{2}$ 1, N-2-hydroxyethylpiperazine-N'-2ethanesulfonic acid - Hepes - 10, and glucose 10) was adjusted to pH 7.4 with tris-(hydroxymethyl)-aminomethane (Tris base), while the patch pipette solution (containing $150 \mathrm{~m} M \mathrm{CsCl}$ and $10 \mathrm{mM}$ Hepes, adjusted with Tris base to $\mathrm{pH}$ 7.2) was used for nystatinperforated patch recordings. A final nystatin concentration of $400 \mu \mathrm{g} / \mathrm{ml}$ dissolved in acidified methanol was added to the patch pipette solution just before use. When the current-voltage $(I-V)$ relationship for $I_{\mathrm{KA}}$ was examined, $0.3 \mu M$ tetrodotoxin and $10 \mu \mathrm{MCdCl}_{2}$ were added to the standard external solution. $\mathrm{CdCl}_{2}$ had no noticeable effect on the $I_{\mathrm{KA}}$ at the concentrations used.

\section{Perforated Patch Recordings}

Electrical measurements were carried out using a nystatin-perforated patch-recording configuration, which maintains the intracellular levels of $\mathrm{Ca}^{2+}$ and other second messengers [15], under voltage-clamp conditions at room temperature $\left(22-25^{\circ} \mathrm{C}\right)$. Patch pipettes were pulled from glass capillaries with an outer diameter of $1.5 \mathrm{~mm}$ (Narishige, Tokyo, Japan) on a two-stage puller (PB-7; Narishige). The resistance between the recording electrode filled with pipette solution and the reference electrode was 4-6 M $\Omega$. The patch pipette was positioned onto a neuronal body using a hydraulic micromanipulator (WR-3; Narishige). The electrode was connected to a patch-clamp amplifier (Axopatch 200A; Axon Instruments, Union City, Calif., USA). Both current and voltage were monitored with a pen recorder (Omniace RT 3100; San-ei, Osaka, Japan), filtered at $1 \mathrm{kHz}$, and sampled and analyzed using a DigiData 1200A interface and a computer running with the pCLAMP 6.0.2 program (Axon Instruments). The morphological and electrophysiological features of the isolated SDCN neurons were similar to those reported previously $[16,17]$. The resting membrane potential was in the range from -45 to $-60 \mathrm{mV}$. The series resistance, estimated from the optimal cancellation of the capacity transient, was 10-30 M $\Omega$. In most experiments, 70-90\% series resistance compensation was applied. The membrane potential was held at $-40 \mathrm{mV}$ throughout the experiment, except when examining the $I-V$ relationship. All measurements were started after stabilization of the KA responses (15-25 min after cell attachment).

\section{Drugs and Statistics}

Pronase was purchased from Calbiochem (La Jolla, Calif., USA), 6-cyano-7-nitroquinoxaline-2-3-dione (CNQX) was from Tocris Neuramin (Bristol, UK), and NS-102 and GYKI 52466 were from Research Biochemicals International (Natick, Mass., USA). The other drugs were from Sigma Chemical (St. Louis, Mo., USA). La was purchased as chloride salt of the highest purity grade available. The drugs were applied via a 'Y tube' [15]. This system allows complete exchange of an external solution surrounding a neuron within $20 \mathrm{~ms}$. All data are expressed as mean values \pm SEM. The data were fitted to a modified Michaelis-Menten equation by use of a least-square fitting for $\mathrm{EC}_{50}$ or $\mathrm{IC}_{50}$ and the Hill coefficient [14]. 
1

Fig. 1. Effects of CNQX, GYKI 52466, and NS-102 on KA-induced whole-cell currents. Inward currents induced by $100 \mu M$ of KA were inhibited by coadministration of $10 \mu M$ CNQX (A), $300 \mu M$ GYKI 52466 (B), but not by $3 \mu M$ NS-102 (C). All antagonists were perfused for $30 \mathrm{~s}$ before simultaneous application of KA. Data in A-C were from different neurons. Similar results were obtained from another 5 neurons.

Fig. 2. A Suppression of the $I_{\mathrm{KA}}$ by $\mathrm{La}^{3+}$ in a concentration-dependent manner. a Currents induced by $100 \mu \mathrm{M}$ of KA in the presence of 1 and $10 \mathrm{mM \textrm {La } ^ { 3 + }}$. b Test of the use dependence of the La block. Currents induced by $100 \mu M$ of KA in the presence of $1 \mathrm{mM} \mathrm{La}{ }^{3+}$ did not decline. The fully developed inhibition of the $I_{\mathrm{KA}}$ observed in the absence of receptor activation indicates that open channels are not required for the La effect. Data shown in $\mathbf{a}$ and $\mathbf{b}$ were from the same neuron. B Concentration-response curve of $\mathrm{La}^{3+}$-induced suppression of the $I_{\mathrm{KA}}$. Each point is the average of the values from 5-7 cells. Here and in the subsequent figures, the vertical bars show the mean \pm SEM.

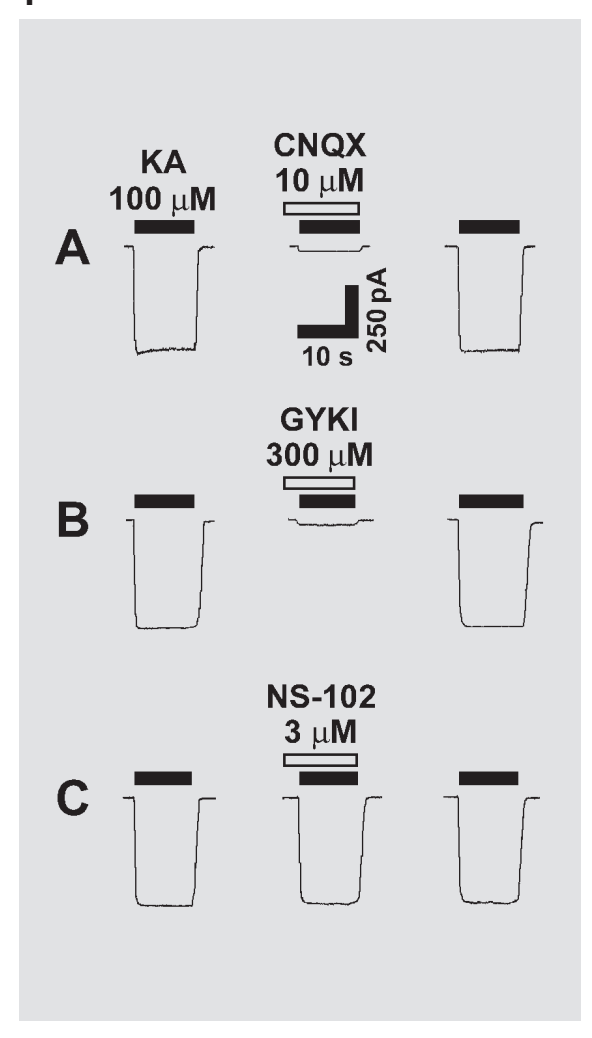

2

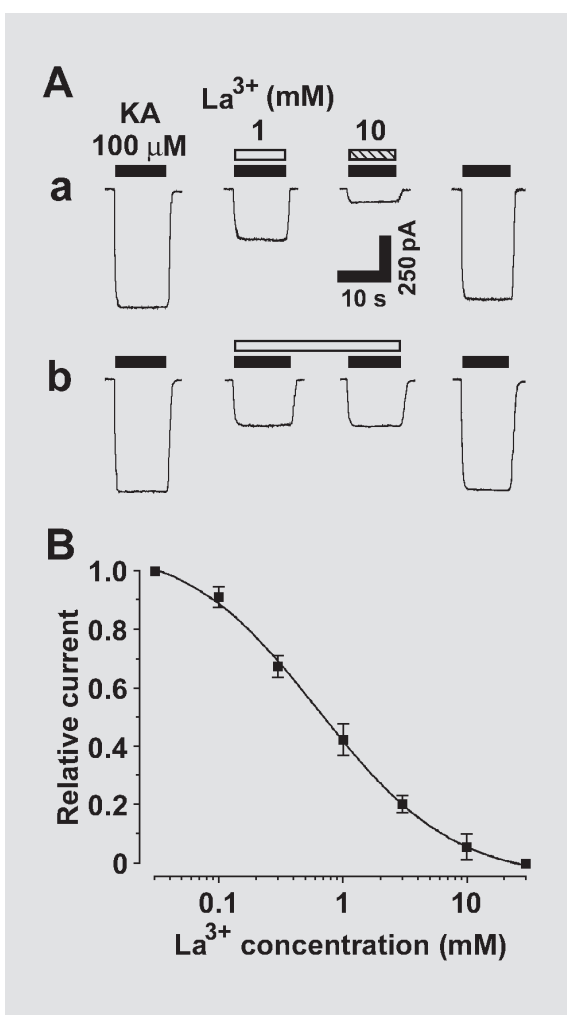

\section{Results}

\section{The KA Responses Were Mediated by AMPA}

Receptors

The application of KA evoked inward currents in all SDCN neurons tested. The inward currents induced by KA did not exhibit noticeable desensitization at the concentrations evaluated. The KA $(100 \mu M)$ induced current was significantly depressed by the selective non-N-methyl- $D$-aspartate (non-NMDA) receptor antagonist CNQX (fig. 1A). Previous work has demonstrated that the nonNMDA receptors include AMPA and KA receptors which are distinct receptor complexes, although both of them can be activated by KA. To examine which subfamily of non-NMDA receptors is present in the acutely dissociated SDCN neurons, the effects of GYKI 52466, the AMPA-receptor-selective noncompetitive antagonist [18], and NS-102, the selective antagonist of KA receptors [19], were investigated. GYKI $52466(300 \mu M)$ reversibly blocked $95 \pm 2 \%$ of the current induced by $100 \mu M$ KA (fig. 1B). In contrast, NS-102 produced no detectable effect on the $I_{\mathrm{KA}}$ (fig. 1C). These data indicated that the responses to KA were mediated by AMPA receptors in SDCN neurons.
Suppression of $\mathrm{I}_{K A}$ by $\mathrm{La}^{3+}$

Under the present experimental conditions for recording $I_{\mathrm{KA}}$, application of $\mathrm{La}^{3+}$ alone induced no noticeable current at levels of up to $30 \mathrm{~m} M$, and with $\mathrm{La}^{3+}$ at $<30 \mu M$, there was not any change in the $I_{\mathrm{KA}}$ detected in SDCN neurons. However, previous reports suggested a modest augmentation of AMPA receptor currents by low concentrations of $\mathrm{La}^{3+}$ (about $15 \mu M$ ) [10-12]. To determine whether there was a small enhancement of current by $<30 \mu M$ of $\mathrm{La}^{3+}$, we next compared the $I_{\mathrm{KA}}$ in the presence and absence of $\mathrm{La}^{3+}$ in CA1 pyramidal neurons of the rat hippocampus. In contrast, in CA1 pyramidal neurons, the $I_{\mathrm{KA}}$, which was mediated by AMPA receptors as confirmed by their significant depression by CNQX and GYKI 52466, was potentiated by about 12\% with $10 \mu M$ of $\mathrm{La}^{3+}$ (data not shown).

In SDCN neurons, the $I_{\mathrm{KA}}$ was inhibited by extracellular coapplication of $\mathrm{La}^{3+}>30 \mu M$. As shown in figure 2A (see a), the amplitudes of $I_{\mathrm{KA}}$ activated by $100 \mu M$ KA decreased with an increase of the $\mathrm{La}^{3+}$ concentration. The suppressive effect of $\mathrm{La}^{3+}$ was rapidly and completely reversed by washing out $\mathrm{La}^{3+}$ in the bathing medium. We further characterized the mechanism of $\mathrm{La}^{3+}$ block by testing whether or not the effect was use dependent, 
Fig. 3. Effects of KA on the block by $\mathrm{La}^{3+}$. A Responses to $100 \mu M$ of KA(a) and $1 \mathrm{~m} M$ of KA (b) under the control condition and in the presence of $1 \mathrm{mM} \mathrm{\textrm {La } ^ { 3 + }}$ in the same neuron. B Plot of the percentage of block by $1 \mathrm{mM} \mathrm{La}{ }^{3+}$ as a function of the KA concentration. C Plot from the same data as in $\mathbf{B}$. The concentration-response curves for KA in the control solution ( $\square$ ) and in the presence of $1 \mathrm{mM} \mathrm{\textrm {La } ^ { 3 + }}(\mathbf{)}$. All responses were normalized to the peak current induced by 100 of $\mu M \mathrm{KA}$ alone $(*)$. Each point is the average of the values from 4-7 neurons.
A
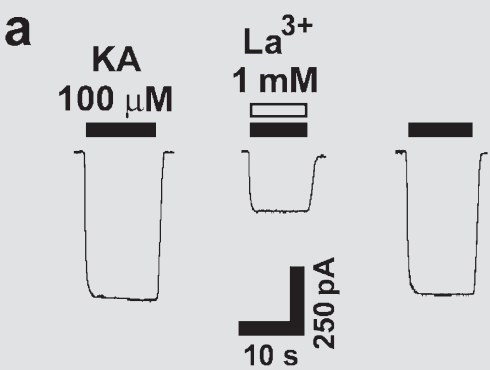

B

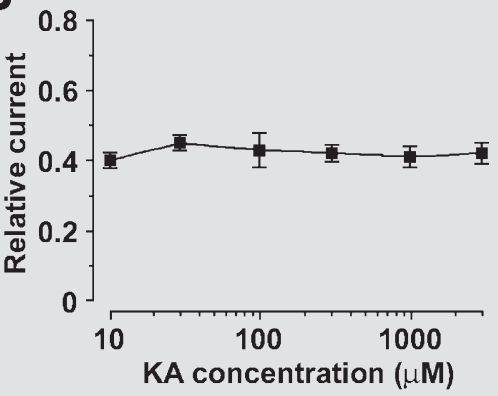

b

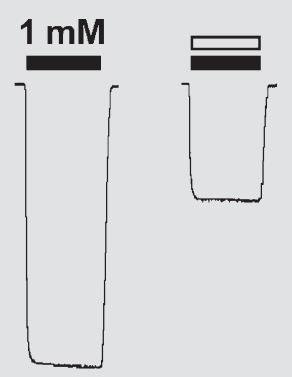

C

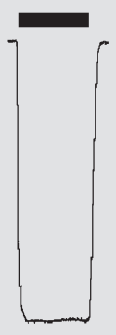

an effect interpreted as being consistent with an open channel blocking mechanism [20]. The magnitude of the inhibitory action of $\mathrm{La}^{3+}$ was not changed by repeated application of $100 \mu \mathrm{M} \mathrm{KA}$ in the continued presence of $1 \mathrm{mM} \mathrm{La}{ }^{3+}$ (fig. 2A; see b), indicating that the full development of $\mathrm{La}^{3+}$ inhibition does not require AMPA receptor channel activation. Thus, the inhibition by $\mathrm{La}^{3+}$ was clearly not dependent on the presence of open channels.

In addition, as shown in figure $2 \mathrm{~B}$, the inhibitory effect of $\mathrm{La}^{3+}$ on the $I_{\mathrm{KA}}$ was concentration dependent from $30 \mu M$ to $30 \mathrm{~m} M$, and significant inhibition of the $I_{\mathrm{KA}}$ was achieved with $\mathrm{La}^{3+}>0.1 \mathrm{~m} M$. With $\mathrm{La}^{3+}>30 \mathrm{mM}$, the $I_{\mathrm{KA}}$ was completely eliminated. The $\mathrm{IC}_{50}$ value obtained from the inhibition curve was $0.64 \pm 0.06 \mathrm{mM}$.

\section{Effect of $\mathrm{La}^{3+}$ on the Concentration-Response Curve of $\mathrm{I}_{K A}$}

The concentration-response curve of $I_{\mathrm{KA}}$ was examined with or without coapplication of $1 \mathrm{mM}$ of $\mathrm{La}^{3+}$ to elucidate the mechanism of the $\mathrm{La}^{3+}$-induced inhibition of $I_{\mathrm{KA}}$. As shown in figure $3 \mathrm{~A}$, the degree of inhibition by $1 \mathrm{mM}$ of $\mathrm{La}^{3+}$ was independent of the KA concentrations. Thus $\mathrm{La}^{3+}$ inhibited the $I_{\mathrm{KA}}$ in a noncompetitive manner. The noncompetitive nature of $\mathrm{La}^{3+}$ was also re- vealed by plotting the current amplitude in the presence of $1 \mathrm{mM} \mathrm{La}{ }^{3+}$ as the ratio of control responses evoked by different concentrations of KA shown in figure $3 \mathrm{~B}$. $\mathrm{La}^{3+}$ reduced the amplitude of KA currents to about $41 \%$ of control values which is independent of the KA concentrations.

Figure 3C shows the dose-response curves for KA under the control condition and after bath application of $\mathrm{La}^{3+} . \mathrm{La}^{3+}$ decreased the maximum value of the concentration response for KA without affecting the threshold concentration. The following values were obtained: $\mathrm{EC}_{50}=108.1 \pm 8.7 \mu \mathrm{M}$ and Hill coefficient $=1.12 \pm 0.10$ in the control solution and $\mathrm{EC}_{50}=107.6 \pm 12.8 \mu \mathrm{M}$ and Hill coefficient $=1.09 \pm 0.12$ in the $\mathrm{La}^{3+}$ solution. $\mathrm{EC}_{50}$ and Hill coefficient for KA were not altered significantly in the presence of $\mathrm{La}^{3+}$, indicating that $\mathrm{La}^{3+}$ did not change the affinity of KA for AMPA receptors.

\section{I-V Relationship of $\mathrm{I}_{K A}$}

To further characterize the $\mathrm{La}^{3+}$ suppression of $I_{\mathrm{KA}}$, the voltage dependence of KA $(100 \mu M)$ induced current was examined in the absence and presence of $1 \mathrm{~m} M$ of $\mathrm{La}^{3+}$ (fig. 4). Representative traces of $I_{\mathrm{KA}}$ inhibited by $\mathrm{La}^{3+}$ at membrane $V_{\mathrm{H}}$ of -40 and $+40 \mathrm{mV}$ are shown in 


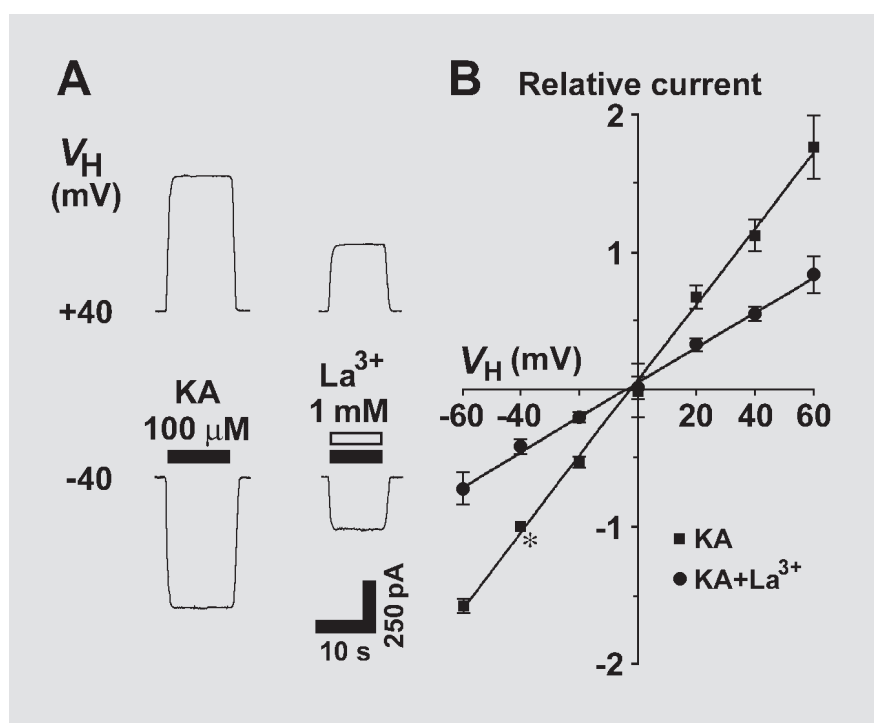

Fig. 4. Effects of $\mathrm{La}^{3+}$ on the $I-V$ relationship for KA. A Responses to $100 \mu M$ of KA at $V_{\mathrm{H}}$ of +40 and $-40 \mathrm{mV}$ under the control condition and in the presence of $1 \mathrm{mMLa} \mathrm{La}^{3+}$. B The $I-V$ relationships of KA responses induced by $100 \mu M$ of KA in the absence $(\boldsymbol{\square})$ and presence $(O)$ of $1 \mathrm{mM}$ of $\mathrm{La}^{3+}$. The inhibitory effect of $\mathrm{La}^{3+}$ is similar at all $V_{\mathrm{H}}$ values. The membrane potential was held at each value for at least $1 \mathrm{~min}$ before application of KA. Currents were normalized to the peak current induced by $100 \mu M$ of KA alone at a $V_{\mathrm{H}}$ of $-40 \mathrm{mV}(*)$. Each point is the mean of the values from 4-8 neurons.

figure $4 \mathrm{~A}$. The $I-V$ curves for $I_{\mathrm{KA}}$ with or without $1 \mathrm{~m} M$ of $\mathrm{La}^{3+}$ are plotted in figure 4B. In the presence of $\mathrm{La}^{3+}$, the linear voltage dependence of $I_{\mathrm{KA}}$ persisted at $V_{\mathrm{H}}$ over $-60 \mathrm{mV}$ to $+60 \mathrm{mV}$, thus the suppression by $\mathrm{La}^{3+}$ was voltage independent. The reversal potentials of KA responses $\left(E_{\mathrm{KA}}\right)$ were $-2.25 \mathrm{mV}$ under the control condition and $-3.90 \mathrm{mV}$ with $1 \mathrm{~m} M$ of $\mathrm{La}^{3+}$. Both of these $E_{\mathrm{KA}}$ values were close to the equilibrium potential for nonspecific cation channels calculated from the given extra- and intracellular cation concentrations, indicating that KA activated nonspecific cation channels in the acutely dissociated SDCN neurons and that $\mathrm{La}^{3+}$ decreased the $I_{\mathrm{KA}}$ without changing the ion selectivity of the AMPA receptor channel.

\section{Discussion}

In the present study, we have demonstrated an inhibitory effect of $\mathrm{La}^{3+}$ on KA-evoked AMPA receptor mediated responses in acutely isolated rat SDCN neurons. The application of $\mathrm{La}^{3+}$ to SDCN neurons suppressed the $I_{\mathrm{KA}}$ in a concentration-dependent manner and reduced the efficacy of KA at AMPA receptors, without affecting both the reversal potential of $I_{\mathrm{KA}}$ and the apparent affinity of $\mathrm{KA}$ to AMPA receptors.

\section{Block of AMPA Receptors by $\mathrm{La}^{3+}$}

In all of the cells that we examined, the whole-cell currents evoked by KA displayed no desensitization. Previous studies have demonstrated that KA evokes nondesensitizing currents through AMPA receptors [10, 13, 21], but faster and more complete desensitization through KA receptors $[22,23]$. In addition, the present pharmacological data demonstrate the antagonism of non-NMDA receptor mediated responses by the AMPA receptor selective, noncompetitive antagonist, GYKI 52466, and the lack of antagonism by the selective antagonist of KA receptor, NS102. Collectively, these results indicate that the KA-evoked currents in SDCN neurons are mediated by activation of AMPA receptors.

Our experiments demonstrate that millimolar $\mathrm{La}^{3+}$ is an efficacious inhibitor of AMPA receptor mediated responses evoked by KA in acutely dissociated SDCN neurons. In contrast, the currents evoked by both native [11] and recombinant [10] KA receptors are strongly inhibited by micromolar $\mathrm{La}^{3+}$. These studies raise the possibility that AMPA- and KA-preferring receptors show differential sensitivity to the inhibition by $\mathrm{La}^{3+}$ and that the much lower potency of antagonism at AMPA receptors makes blockade by the ion a useful diagnostic tool for distinguishing currents mediated by the AMPA and KA subtypes.

In addition, the action of $\mathrm{La}^{3+}$ on neural AMPA receptors in SDCN neurons described here seems to be different from the dual action of this ion on AMPA receptors which was reported previously in rat DRG, cultured rat hippocampal and cortical neurons [10,11], and rat dorsal horn neurons [12]. Previous work showed that currents mediated by AMPA receptors were blocked with $\mathrm{La}^{3+}$ levels $>100 \mu M$, but were potentiated by micromolar $\mathrm{La}^{3+}$ [10-12]. However, we only observed the inhibitory action of $\mathrm{La}^{3+}$ on AMPA receptors in SDCN cells. In addition, the modest augmentation of AMPA receptor currents by low concentrations of $\mathrm{La}^{3+}$ was observed in CA1 pyramidal neurons of the rat hippocampus under the same experimental conditions. The results suggest that AMPA receptors in SDCN neurons are pharmacologically distinct from those in other neurons, and the conspicuous difference seen between the distinct cell types also sug- 
gests that the lack of enhancement of current by $<30 \mu M$ of $\mathrm{La}^{3+}$ is not a result of our recording or analysis techniques. However, the reason for this discrepancy remains unclear. One possible explanation is that the difference may reflect the heterogeneity of AMPA receptors expressed in different preparations. Future work should focus on the identification of subunit domains specific to AMPA receptors that underlie the inhibitory effect of $\mathrm{La}^{3+}$.

\section{Mechanism of Block}

Our experiments demonstrate that the degree of inhibition of the $I_{\mathrm{KA}}$ by $\mathrm{La}^{3+}$ does not depend on the KA concentration. Similar findings have been discussed for the block of glutamate receptors in DRG neurons by $\mathrm{La}^{3+}$ [11] and for the inhibition of $\gamma$-aminobutyric acid type A receptors in DRG neurons by copper [24]. The failure of increasing KA concentrations to overcome the inhibition by $\mathrm{La}^{3+}$ suggests that the inhibition does not involve either competition for the agonist-binding site or a reduction in the effective concentration of KA which might occur with direct interaction between $\mathrm{KA}$ and $\mathrm{La}^{3+}$. In addition, in the present study, $\mathrm{La}^{3+}$ produced a nearly $59 \%$ decrease in the maximal and half-maximal currents with the same $\mathrm{EC}_{50}$ in comparison with that under $\mathrm{La}^{3+}$ free conditions, suggesting that $\mathrm{La}^{3+}$ changes the number of AMPA receptors available or decreases the open frequency of the AMPA receptors. Collectively, the properties of the $\mathrm{La}^{3+}$-induced block are more consistent with an allosteric model of action, in which $\mathrm{La}^{3+}$ binds to a distinct site on the AMPA receptor and reduces the potency of KA.

To further characterize the mechanism of $\mathrm{La}^{3+}$ inhibition of $I_{\mathrm{KA}}$, we observed the relationship between the KA current and the membrane potential in the absence and presence of $\mathrm{La}^{3+}$. Our data indicated that the inhibitory effect of $\mathrm{La}^{3+}$ is similar, as the $V_{\mathrm{H}}$ varied from -60 to $+60 \mathrm{mV} . \mathrm{La}^{3+}$ did not change the linear dependence of KA current on the membrane potential. Open-channel block by cations is often voltage dependent [25], so the lack of voltage dependence of $\mathrm{La}^{3+}$ block on the $I_{\mathrm{KA}}$ makes it unlikely that $\mathrm{La}^{3+}$ exerts a blockade of the open channel by entering the pore. Furthermore, the time course of current inhibition gave little indication that the channels had to be open in order for the ions to bind or unbind from their site of action [20,26]. Hence, the ion may bind to a superficial site near or at external orifices of the channel. Not only glutamate receptors, but also $\gamma$-aminobutyric acid type A [5-7], glycine [8], and acetylcholine [9] receptors can be modulated by $\mathrm{La}^{3+}$. The multiplicity of the $\mathrm{La}^{3+}$ action also suggests that more than one mechanism is likely to be involved in the modulation of synaptic currents by $\mathrm{La}^{3+}$. Further work will be needed to understand the structural and mechanistic bases of the multiplicity.

In summary, our results demonstrate that $\mathrm{La}^{3+}$ is an efficacious inhibitor of AMPA receptor mediated responses evoked by KA in SDCN neurons. In addition, the use of La has expanded, and the greater use of it increased the chances of exposure. Calculations made by Briner et al. [3] suggest that the concentration of $\mathrm{La}^{3+}$ in the CNS after exposure to $\mathrm{La}$ in food or drinking water may reach $0.7 \mathrm{~m} M$. Thus, it seems that the $\mathrm{IC}_{50}$ values of $\mathrm{La}^{3+}$ determined here are within the limits that may be expected to occur in vivo by La exposure. The data in the present work add further diversity to the mechanisms of the cytotoxic effects of $\mathrm{La}^{3+}$.

\section{Acknowledgments}

This work was supported by the National Natural Science Foundation of China (grant No. 30300077) and a grant from the Fourth Military Medical University to Dian-Shi Wang. We are very grateful to Drs. Zhi-Ming Wang and Hui Li for their technical assistance.

\section{References}

1 Abramczuk JW: The effects of lanthanum chloride on pregnancy in mice and on preimplantation mouse embryos in vitro. Toxicology 1985;34:315-320.

2 Smedley MJ, Stanisstreet M: Calcium and neurulation in mammalian embryos. J Embryol Exp Morphol 1985;89:1-14.

3 Briner W, Rycek RF, Moellenberndt A, Dannull K: Neurodevelopmental effects of lanthanum in mice. Neurotoxicol Teratol 2000;22: $573-581$.
4 Das T, Sharma A, Talukder G: Effects of lanthanum on cellular systems: A review. Biol Trace Elem Res 1988;18:201-228.

5 Kolbaev SN: Modulation of GABA-activated currents in rat isolated cerebellar neurons by lanthanum ions. Bull Exp Biol Med 2002;133: 44-47.

6 Brown N, Kerby J, Bonnert TP, Whiting PJ, Wafford KA: Pharmacological characterization of a novel cell line expressing human $\alpha 4 \beta 3 \delta$ GABA $_{A}$ receptors. Br J Pharmacol 2002;136:965-974.
7 Barila B, Cupello A, Robello M: Modulation by lanthanum ions of $\gamma$-aminobutyric acid a receptors of rat cerebellum granule cells in culture: Clues on their subunit composition. Neurosci Lett 2001;298:13-16.

8 Kumamoto E, Murata Y: Glycine current in rat septal cholinergic neuron in culture: Monophasic positive modulation by $\mathrm{Zn}^{2+}$. J Neurophysiol 1996;76:227-241. 
9 Inoue R, Morita H, Yanagida H, Ito Y: Potentiating actions of lanthanum on $\mathrm{ACh}$-induced cation current in guinea pig ileal smooth muscle cells. J Smooth Muscle Res 1998;34:6981.

10 Wilding TJ, Huettner JE: Activation and desensitization of hippocampal kainate receptors. J Neurosci 1997; 17:2713-2721.

11 Huettner JE, Stack E, Wilding TJ: Antagonism of neuronal kainate receptors by lanthanum and gadolinium. Neuropharmacology 1998; 37:1239-1247.

12 Reichling DB, MacDermott AB: Lanthanum actions on excitatory amino acid-gated currents and voltage-gated calcium currents in rat dorsal horn neurons. J Physiol 1991;441:199218.

$13 \mathrm{Xu} \mathrm{TL}, \mathrm{Li}$ JS, Akaike N: Functional properties of ionotropic glutamate receptor channels in rat sacral dorsal commissural neurons. Neuropharmacology 1999;38:659-670.

$14 \mathrm{Xu}$ TL, Dong XP, Wang DS: N-methyl- $D$-aspartate enhancement of the glycine response in the rat sacral dorsal commissural neurons. Eur J Neurosci 2000; 12:1647-1653.

15 Akaike N, Harata N: Nystatin perforated patch recording and its applications to analyses of intracellular mechanisms. Jpn J Physiol 1994; 44:433-473.
16 Lu Y, Inokuchi H, McLachlan EM, Li JS, Higashi $\mathrm{H}$ : Correlation between electrophysiology and morphology of three groups of neuron in the dorsal commissural nucleus of lumbosacral spinal cord of mature rats studied in vitro. J Comp Neurol 2001;437:156-169.

17 Xu TL, Nabekura J, Akaike N: Protein kinase C-mediated enhancement of glycine response in rat sacral dorsal commissural neurones by serotonin. J Physiol 1996;496(Pt 2):491-501.

18 Donevan SD, Rogawski MA: GYKI 52466, a 2,3-benzodiazepine, is a highly selective, noncompetitive antagonist of AMPA/kainate receptor responses. Neuron 1993;10:51-59.

19 Verdoorn TA, Johansen TH, Drejer J, Nielsen EO: Selective block of recombinant glur6 receptors by NS-102, a novel non-NMDA receptor antagonist. Eur J Pharmacol 1994;269:4349.

20 Nabekura J, Murata O, Ishibashi H, Akaike N: Use-dependent suppression of the nicotinic acetylcholine receptor response by the proadrenomedullin $\mathrm{N}$-terminal 20 -amino acid peptide in rat locus coeruleus neurons. J Neurochem 1998;70:865-870.

21 Patneau DK, Mayer ML: Kinetic analysis of interactions between kainate and AMPA: Evidence for activation of a single receptor in mouse hippocampal neurons. Neuron 1991;6: 785-798.
22 Herb A, Burnashev N, Werner P, Sakmann B, Wisden W, Seeburg PH: The KA-2 subunit of excitatory amino acid receptors shows widespread expression in brain and forms ion channels with distantly related subunits. Neuron 1992;8:775-785.

23 Boulter J, Hollmann M, O’Shea-Greenfield A, Hartley M, Deneris E, Maron C, Heinemann $\mathrm{S}$ : Molecular cloning and functional expression of glutamate receptor subunit genes. Science 1990;249:1033-1037.

24 Ma JY, Narahashi T: Differential modulation of $\mathrm{GABA}_{\mathrm{A}}$ receptor-channel complex by polyvalent cations in rat dorsal root ganglion neurons. Brain Res 1993;607:222-232.

25 Kolbaev SN, Sharonova IN, Vorobjev VS, Skrebitsky VG: Mechanisms of $\mathrm{GABA}_{\mathrm{A}}$ receptor blockade by millimolar concentrations of furosemide in isolated rat Purkinje cells. Neuropharmacology 2002;42:913-921.

26 Zitron E, Karle CA, Wendt-Nordahl G, Kathofer S, Zhang W, Thomas D, Weretka S, Kiehn J: Bertosamil blocks HERG potassium channels in their open and inactivated states. Br J Pharmacol 2002;137:221-228. 